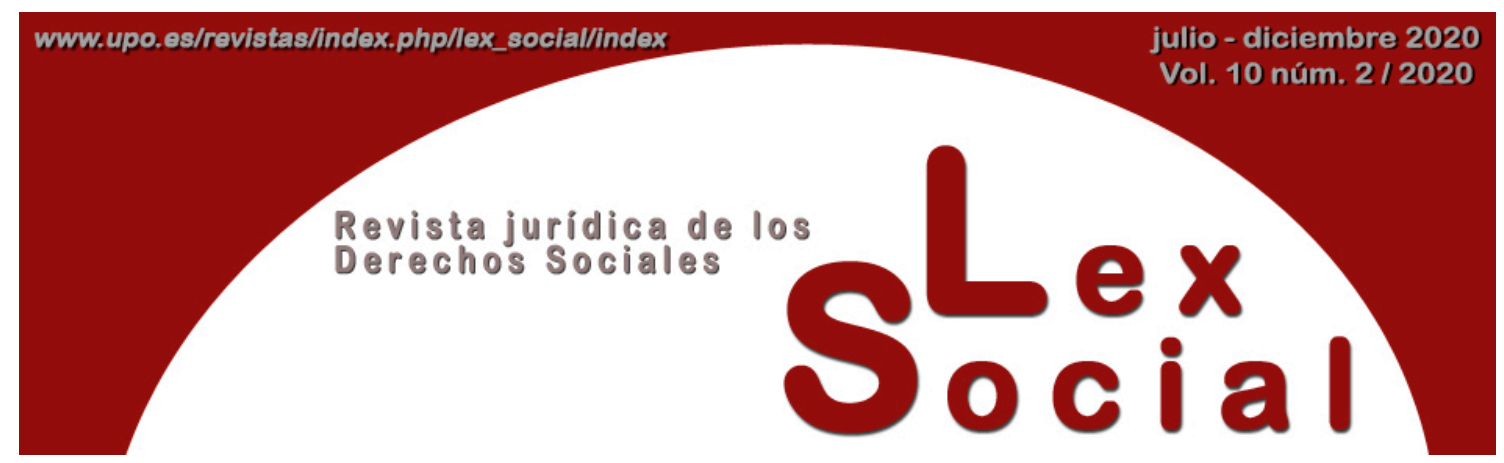

\title{
LA REGULACIÓN SOCIAL TRANSNACIONAL DE LAS EMPRESAS MULTINACIONALES
}

\section{THE TRANSNATIONAL LABOUR REGULATION OF MULTINATIONAL ENTERPRISES}

\author{
JEAN-MICHEL SERVAIS \\ Profesor invitado de la Universidad de Girona \\ Presidente de honor de la Sociedad Internacional de Derecho del Trabajo \\ y de la seguridad Social. Ex-director de la OIT
}

Artículo recibido el 10 de mayo de 2020

Artículo aceptado el 1 de junio de 2020

DOI: https://doi.org/10.46661/lexsocial.5065

\begin{abstract}
RESUMEN
El enorme poder financiero que han adquirido las multinacionales no solo ha desestabilizado a las personas, sino también a los Estados, que pierden su capacidad para decidir solos sus políticas económicas y sociales, y a las organizaciones internacionales, cuyos poderes provienen de los Estados. Frente a esta situación compleja, resulta muy importante la existencia de una regulación transnacional adecuada. Varios instrumentos legales completan los derechos nacionales del trabajo y el derecho de la OIT, los mejoran, sin sustituirlos o transformarlos, porque también tienen sus defectos. Las soluciones actuales y sus debilidades constituirán el objeto de la primera y de la segunda parte respectivamente del artículo. Las conclusiones contienen algunas sugerencias para superar mejor las consecuencias sociales negativas de la globalización.
\end{abstract}

Palabras Clave: Empresas multinacionales, regulación, OIT, códigos de conducta, responsabilidad social corporativa de la empresa. 


\begin{abstract}
The considerable financial power acquired by the multinational enterprises has destabilized, in addition to the people, the States that lose their ability to decide alone of their economic and social policies as well as the international organizations whose capacities come from those of the States. This intricate situation underlines the need for adequate transnational regulation. Distinct legal instruments complete national labour legislation and the ILO law, improve them, without substituting or transforming them as they also have their shortcomings. The current solutions and their weaknesses will be the object of the first and second part respectively of this contribution. The conclusions contain some suggestions to better overcome the negative social consequences of globalization.
\end{abstract}

KEYWORDS: Multinational corporations, regulation, ILO, codes of conduct, corporate social responsibility.

SUMARIO

I. Problemática.

II. Soluciones actuales.

1. Códigos tipos y normas de gestión.

1.1. Códigos modelos.

A. OCDE: Las líneas directrices para empresas multinacionales

B. OIT: Las Declaraciones a) de principios tripartita sobre las empresas

multinacionales y la política social y b) relativa a los Principios y Derechos

Fundamentales en el Trabajo

C. ONU: El Pacto mundial y los Principios Rectores sobre las Empresas y los

Derechos Humanos

D. Iniciativas del Banco mundial y de su grupo

E. Iniciativas europeas

F. Iniciativas nacionales

1.2. Normas de gestión.
A. Etiquetado social
B. Programas de acreditación y de certificación
C. Informes sociales
D. Inversiones socialmente responsables 


\section{Códigos operacionales.}

III. Límites de la regulación actual.

1. Limites estratégicos de las reglas de RSE.

2. Limites técnicos de la RSE.

3. Implementación de las reglas privadas de trabajo.

a) Efectos jurídicos

b) Supervisión

\section{Primeras conclusiones.}

$I V$. Reflexiones finales para un futuro mejor.

Bibliografía

Anexo

\section{Problemática.}

Es una problemática muy conocida. El enorme poder financiero que han adquirido las multinacionales no solo ha desestabilizado a las personas, sino también a los Estados, que pierden su capacidad para decidir solos sus políticas económicas y sociales, y a las organizaciones internacionales, cuyos poderes provienen de los Estados ${ }^{1}$. Un Estado, incluso industrializado, encuentra dificultades para imponer el respeto a sus reglas jurídicas a las entidades de carácter transnacional.

La internacionalización de los intercambios también ha debilitado a las asociaciones empresariales y sindicales nacionales que participan de una manera u otra en la aplicación efectiva de las normas de trabajo. Los problemas de las organizaciones de trabajadores son a veces bastante preocupantes, con la caída de la afiliación. Las asociaciones patronales conocen también serias dificultades, porque las pequeñas y medianas empresas tienen unos intereses muy diferentes de los de las grandes.

El derecho del trabajo resulta afectado tanto en su contenido como en su ejecución ${ }^{2}$. Por un lado, muchos gobiernos adoptan una política de desregulación, con el fin de atraer las

\footnotetext{
${ }^{1}$ LANTARÓN BARQUÍN, David, “Estándares laborales internacionales en la era de la globalización”, Trabajo y Derecho, 2017, n 28, pp. 35-56; SANGUINETI RAYMOND, Wilfredo, VIVERO SERRANO, Juan Bautista (Dir.), La construcción del derecho del trabajo de las redes empresariales, Granada, Editorial. Comares, 2019; SERVAIS, Jean-Michel, "Los estándares laborales de la OIT en el contexto de la crisis”, en GIL Y GIL, José Luis, Reformas laborales frente a la crisis a la luz de los estándares de la OIT. Un análisis crítico desde las perspectivas internacional, nacional y comparada, Lisboa, Juruá Editorial, 2014, pp. 19-53.

${ }^{2}$ CLAUWAERT, Stefan, SCHÖMANN, Isabelle, “The crisis and national labour law reforms. A mapping exercice”, European Labour Law Journal, 2012, vol. 3, n 1, pp. 54-69.
} 
inversiones. Si no lo hacen, evitan controlar estrictamente las operaciones de las multinacionales, o lo hacen solo cuando ocurre un evento grave, como el caso del Rana Plaza. Por otro, el carácter supranacional de muchas empresas tiende a alejar cada vez más el poder de decisión del lugar de trabajo. Las decisiones importantes no se toman en el país de la ley aplicable, sino a nivel central. Si la negociación del salario se celebra local o nacionalmente, los representantes de la dirección no poseen una autoridad suficiente para modificar la cuantía de la masa salarial global que fija la dirección general.

Algunas empresas, aunque todavía pocas, ni siquiera tienen vínculos especiales con un lugar específico. Sitúan su sede central allí donde se encuentran, en un determinado momento, sus principales directivos. A veces, en particular en las industrias del petróleo y minera, se las acusa de escapar de cualquier legislación laboral. También se plantean otras cuestiones. Imaginamos qué rompecabezas puede ser para ellas la protección estrictamente nacional, incluso europea, de las invenciones y creaciones dentro del ámbito laboral.

Más en general, no siempre es clara la determinación de la ley aplicable en el derecho o en la práctica. Cada país tiene su propio derecho internacional privado, que determina la jurisdicción competente y la ley aplicable. La misma problemática se aplica a las disposiciones de los convenios internacionales del trabajo ratificados por un país, porque se integran en su legislación nacional (de manera diferente en los sistemas monista o dualista).

Frente a esta situación compleja, resulta muy importante la existencia de una regulación transnacional adecuada ${ }^{3}$. Varias disposiciones completan los derechos nacionales del trabajo y el derecho de la OIT, los mejoran, sin sustituirlos o transformarlos, porque también tienen sus defectos. Las soluciones actuales y sus debilidades constituirán el objeto de la primera y de la segunda parte respectivamente del artículo. En las conclusiones, expresaré algunas sugerencias para superar mejor las consecuencias sociales negativas de la globalización.

\section{Soluciones actuales.}

Existe una tendencia, en el derecho transnacional del trabajo, a multiplicar los procedimientos, las técnicas, las instancias de control. Esta abundancia conduce a una proliferación de tipos de supervisión, tales como el etiquetado social, la acreditación social u otros métodos de certificación, o los informes sociales corporativos, que compiten con métodos más tradicionales. Las organizaciones internacionales han tomado

\footnotetext{
${ }^{3}$ GIL Y GIL, José Luis, "Globalización y universalidad del derecho: la lex mercatoria y el derecho internacional del trabajo en el mercado global”, Revista Internacional y Comparada de Relaciones Laborales y Derecho del Empleo, 2016, vol. 4, nº 2, pp. 23 ss; LANTARÓN BARQUÍN, David, La tutela internacional del trabajador: categorías y estrategias. El trabajo decente como telón de fondo, Valencia, Tirant lo Blanch, 2019; SANGUINETI RAYMOND, Wilfredo, "Las cadenas mundiales de producción y la construcción de un derecho del trabajo sin fronteras", en Asociación española de derecho del trabajo y de la seguridad social, El futuro del trabajo: cien años de la OIT, Madrid, Ministerio del trabajo, migraciones y seguridad social, 2019, pp. 25-77.
} 
nota de la importancia adquirida por los protagonistas privados; han elaborado códigos de conducta, destinados a influenciar las firmas en sus políticas sociales. Han redactado directrices al respecto: la Organización para la Cooperación y el Desarrollo Económicos (OCDE), la Organización internacional del trabajo (OIT) y, más recientemente, las Naciones Unidas, con el Pacto Global o los Principios Rectores de J. Ruggie sobre las empresas y los derechos humanos. También tratan de promover iniciativas del mismo tipo otras entidades internacionales, como el Banco Mundial, o la Unión europea, y algunos gobiernos, como Bélgica, Canadá, los Estados Unidos, Francia, los Países Bajos, o el Reino Unido.

Por otro lado, el debilitamiento del poder estatal ha estimulado a los sindicatos y otras ONG a presionar a las empresas para que reconozcan su responsabilidad social y analicen las consecuencias de sus actividades sobre la calidad de vida de los trabajadores y de las comunidades locales en las cuales operan ${ }^{4}$. La responsabilidad social empresarial (RSE) puede definirse como el reconocimiento por parte de las empresas de una obligación de ofrecer condiciones laborales y ambientales decentes.

El respeto de una regulación social transnacional se funda sobre bases éticas y sociales incontestables, es decir, sobre la preocupación de los empresarios de seguir y promover reglas cívicas en sus relaciones con los trabajadores, los vecinos y las autoridades locales o nacionales. De hecho, se apoya igualmente sobre la constatación de que unas buenas condiciones de empleo estimulan el rendimiento ${ }^{5}$. Corresponde finalmente a la voluntad de presentar al público y de conservar una imagen de excelencia, que se vería enturbiada por la utilización de métodos de producción que provocan la reprobación. La práctica ha demostrado que una conducta inapropiada puede provocar campañas de prensa y de boicot lanzadas por organizaciones de trabajadores, asociaciones de consumidores u otros grupos sociales ${ }^{6}$.

Las sociedades comerciales pueden inspirarse en códigos modelos propuestos por diferentes instituciones y grupos. Pueden obtener certificados de buena honorabilidad social de una autoridad exterior. A veces, los dos tipos de iniciativas coexisten (1). Ciertas empresas se comprometen a aplicar reglas mínimas de trabajo en los contratos mercantiles que firman con sus proveedores, subcontratistas, concesionarios o clientes; más a menudo - pero una posibilidad no impide la otra - lo hacen dentro del marco de la empresa o del

\footnotetext{
${ }^{4}$ DE QUENAUDON, René, Droit de la responsabilité sociétale des organisations (RSO), Bruselas, Larcier, 2014; CHANTEAU, Jean-Pierre, CHENUT-MARTIN, Kathia, CAPRON, Michel (Dir.), Entreprise et responsabilité sociale en question: savoir et controverses, París, Garnier (Classiques), 2017; MALECKI, Catherine, Responsabilité sociale des entreprises. Perspectives de la gouvernance d'entreprise durable, París, L.G.D.J., 2014; FARRARESI, Marco, Responsabilità sociale dell'impresa e diritto del lavoro, Milano, Cedam, 2012; GENDRON, Corinne, GIRARD, Bernard (Dir.), Repenser la responsabilité sociale de l'entreprise: l'école de Montréal, París, Colin, 2013.

${ }^{5}$ Véase por ejemplo MEYER-BISCH, Patrice, FRIBOULET, Jean-Jacques, DAVOINE, Eric (Dir.), L'effectivité des normes sociales internationales dans l'activité économique, Bruselas, Bruylant, París, LGDJ, Zúrich, Schultess, 2008.

${ }^{6}$ GIACONI, Marta, GIASANTI, Lorenzo, VARVA, Simone, "The value of social reputation the protection of MNEs' workers through consumers' eyes”, XXII Congreso mundial de derecho del trabajo y de la seguridad social (Turín, 4-7 de septiembre 2018), http://www.islssltorino2018.org/papers/
} 
grupo, en documentos que se suman, a este nivel, al reglamento del establecimiento. Estas últimas medidas han recibido frecuentemente la denominación genérica de "códigos de conducta” (2).

\section{Códigos tipos y normas de gestión.}

\subsection{Códigos modelos.}

Se pueden distinguir dos clases.

Los primeros, que promueven instituciones privadas como ONGs, asociaciones de empresas, sindicatos o consultores, pretenden materializar el compromiso social de diferentes partes interesadas, junto con la empresa. Crean un marco que debe ayudarles a asegurar su seguimiento, fijando objetivos, identificando indicadores y sugiriendo procedimientos de informes para garantizar la eficacia del sistema.

La figura más conocida en esta categoría es el modelo ISO (sigla en inglés de Organización internacional de estandarización), que elabora principalmente normas de calidad y de medio ambiente. En el campo social, la norma ISO precisa las medidas preventivas y correctivas que deben adoptarse, favorece las mejoras continuas, y se concentra en los sistemas de gestión y documentación que demuestran la eficacia de los métodos elegidos.

La norma ISO 26000:2010 contiene líneas directrices relativas a la responsabilidad social. Entre otros campos, se refiere a los derechos económicos, sociales y culturales, así como a los principios y derechos fundamentales en el trabajo. Trata de las relaciones y condiciones de trabajo, el empleo, las relaciones entre el empresario y el trabajador, la protección social, el dialogo social, la seguridad y salud laboral y el desarrollo de los recursos humanos ${ }^{7}$.

La ISO está elaborando una nueva "norma” - ISO 45001 - relativa a los sistemas de gestión de la salud laboral, con el fin de aliviar esta obligación para las empresas, estableciendo un marco de referencia para la mejora de la seguridad y de la higiene de los trabajadores en el mundo entero. Aunque con un éxito limitado, participan en su trabajo la OIT, la Organización internacional de los empresarios (OIE) y la Confederación sindical internacional (CSI).

Las segundas normas las elaboran entidades públicas. Desde hace mucho tiempo, las instituciones internacionales o nacionales han establecido principios rectores dirigidos a inspirar las políticas sociales de las empresas. Les dedicaré los párrafos que siguen.

\section{A. OCDE: Las líneas directrices para empresas multinacionales.}

La OCDE adoptó en 1976 una Declaración sobre inversiones internacionales y empresas multinacionales. El documento, y las decisiones que han seguido, constituyen un compromiso político, asumido por los gobiernos de los Estados miembros, de mejorar el clima de las aportaciones extranjeras de fondos, de favorecer la contribución positiva de

\footnotetext{
7 Véase el sitio iso.org. Véase también CAPRON, Michel, QUAIREL-LANOIZELÉE, Françoise, TURCOTTE, Marie-France, Iso 26000: une Norme Hors Norme?, París, Economica, 2011.
} 
las multinacionales al progreso económico y social, y de resolver, o, al menos, reducir al mínimo, las dificultades que resultan de sus operaciones. De forma regular, se revisan tanto la declaración como las decisiones adoptadas sobre su base.

La Declaración incluye unas líneas directrices que tienen el carácter de recomendaciones sin valor obligatorio, y que se dirigen a las empresas por los gobiernos que las han suscrito. La observación de estas disposiciones es voluntaria y se anima a aplicarlas mediante puntos de contacto nacionales.

Las directrices cubren el abanico de las actividades de las sociedades multinacionales y se apoyan sobre procedimientos de implementación en 48 países, el 2 de junio de 2020, miembros y no miembros de la Organización. Las completan comentarios explicativos y clarificaciones sobre su interpretación, junto a las deliberaciones del Comité de las inversiones internacionales y de las empresas multinacionales.

El documento empieza con consideraciones generales sobre el respeto de los derechos humanos, sobre la importancia de la formación profesional, el cumplimiento de las reglas de la legislación nacional y sobre la información del personal. Siguen recomendaciones en muchas materias, como el medio ambiente, la lucha contra la corrupción, la publicación de informaciones, el interés de los consumidores, la competencia, la ciencia y la tecnología. En lo que concierne el empleo y las relaciones laborales, el instrumento se refiere a los derechos fundamentales en el trabajo consagrados por la OIT: ausencia de discriminación, abolición del trabajo forzoso e infantil, libertad sindical y negociación colectiva. Menciona explícitamente la Declaración adoptada en 1998 por de la Organización sobre el tema.

Es muy explícito sobre las relaciones colectivas, cuando pide que los representantes de los trabajadores reciban toda la información necesaria y facilidades para llevar a cabo las negociaciones. El texto se refiere expresamente a los cambios importantes que pueden ocurrir en la empresa, como el cierre de un establecimiento, y condena las amenazas a transferir una o más entidades operacionales fuera del país, durante las discusiones colectivas. Cita también la salud y la seguridad en el trabajo. Sugiere, en el párrafo 13, que las empresas animen a sus colaboradores comerciales, incluso los proveedores y los subcontratistas, a aplicar reglas de comportamiento conformes a las Líneas directrices.

Los comentarios que acompañan al documento se refieren a la Declaración tripartita de la OIT sobre las empresas multinacionales y la política social. Precisan que las Líneas directrices de la OCDE juegan un papel de promoción para que las multinacionales observen la otra Declaración de la OIT, el instrumento de 1998. Subraya que tanto las directrices como la Declaración de la OIT sobre las multinacionales se refieren al comportamiento esperado de las empresas. Siendo más detallada, la Declaración de la OIT es "útil” para la buena comprensión de las directrices, aunque los procedimientos de seguimiento no son de la competencia de los mismos órganos.

Además, los comentarios señalan los instrumentos de la OIT sobre la abolición del trabajo infantil (convenios núm. 138 y 182; recomendación núm. 146) y del trabajo forzoso (convenios núm. 29 y 105), la eliminación de la discriminación en el empleo y la 
profesión (convenio núm. 111, convenios núm. 183 sobre la protección de la maternidad y 159 sobre la readaptación profesional y el empleo de las personas inválidas, así como las recomendaciones núm. 162 sobre los trabajadores de edad y 200 sobre el VIH y el sida). Mencionan igualmente las recomendaciones núm. 94, sobre la consulta y la colaboración entre empleadores y asalariados al nivel de la empresa; 198, sobre la relación de trabajo; 194, sobre la lista de enfermedades profesionales, y 195, sobre el desarrollo de los recursos humanos.

\section{B. OIT: Las Declaraciones a) de principios tripartita sobre las empresas multinacionales y la política social y b) relativa a los Principios y Derechos Fundamentales en el Trabajo.}

El desarrollo de las firmas transnacionales en los años sesenta y setenta ha suscitado debates intensos en los foros internacionales, incluso en la OIT. La dificultad de reconciliar los puntos de vista descartó la posibilidad de redactar un convenio internacional sobre el tema. El Consejo de administración de la Organización optó en 1977 por una declaración, instrumento no obligatorio, que ha revisado después ${ }^{8}$. El texto empieza con algunos párrafos explicativos y de políticas generales y trata sucesivamente de cuestiones de empleo (seguridad y promoción del empleo, seguridad social, abolición del trabajo forzoso e infantil; igualdad de oportunidades y de trato, formación), de condiciones de trabajo y de vida (incluso prestaciones, salarios, seguridad y salud) y de relaciones colectivas (libertad sindical, negociación colectiva, consultas, examen de las reclamaciones y solución de conflictos).

Las empresas, incluidas las empresas multinacionales, deberían proceder con la debida diligencia para detectar, prevenir y mitigar sus consecuencias negativas reales o potenciales sobre los derechos humanos reconocidos internacionalmente, que abarcan en particular los derechos enunciados en los Pactos de la Naciones Unidas sobre los Derechos Humanos y en la Declaración de la OIT relativa a los principios y derechos fundamentales en el trabajo. Esta última disposición, introducida en 2017, consagra un principio de responsabilidad basada en la influencia ("leverage” en inglés) de la empresa, derivada de los Principios Rectores sobre las Empresas y los Derechos Humanos, que se examinará más adelante.

La Declaración tiene por objeto fomentar la contribución positiva que las multinacionales pueden aportar al progreso económico y social, y minimizar y resolver las dificultades a que pueden dar lugar sus operaciones. Insiste sobre el carácter voluntario del documento, que intenta guiar a los gobiernos y a las organizaciones empresariales y sindicales, sin obligarlos a observar estos principios. El anexo I contiene una lista de instrumentos a los cuales se refiere el documento, método que permite subrayar la importancia de los mismos. El anexo II menciona una serie de herramientas prácticas, que comprenden un

\footnotetext{
${ }^{8}$ GIL Y GIL, José Luis, “La dimensión social de la globalización en los instrumentos de la OIT”, Revista Internacional y Comparada de Relaciones Laborales y Derecho del Empleo, 2017, vol. 5, n 1, pp. 29-34; G. Minet, A. Guamán Hernández, “L'OIT peut-elle relever le défi des multinationales?”, Revue de droit du travail, février 2020, pp. 84-90.
} 
mecanismo de seguimiento regional, la designación de puntos focales nacionales sobre una base tripartita, el diálogo entre las empresas y los sindicatos y el procedimiento de interpretación. La OIT suministra también su asistencia a nivel de país a los gobiernos, empleadores y trabajadores.

La OIT ha establecido programas específicos para promover esta Declaración. Más en general, la Organización tiene actividades importantes en materia de responsabilidad social empresarial. Ha creado un servicio de asistencia para proporcionar asesoramiento especializado sobre la aplicación del texto y, además, de sus normas de trabajo. Ciertas peticiones vienen de agencias internacionales como el Banco mundial o de autoridades nacionales, como el USAID. La Organización impulsa la puesta en práctica de su instrumento no solo a través de proyectos de asistencia técnica realizados con gobiernos y asociaciones profesionales, sino también de colaboraciones de tipo "público-privado" con gobiernos y multinacionales, como Volkswagen y varias empresas transnacionales españolas. También recibe peticiones para suministrar informaciones técnicas sobre los aspectos sociales de los códigos de conducta.

La Declaración ya mencionada de 1998 sobre los Principios y Derechos Fundamentales en el Trabajo tiene el potencial de ir más allá del marco puramente interestatal, aunque está esencialmente dirigida a los Estados Miembros de la Organización. Se concentra en todos los derechos sociales fundamentales previamente mencionados, que enumera aunque sin detallar los medios específicos para su implementación. Su valor vinculante es muy limitado, y los procedimientos de seguimiento claramente menos exigentes que los mecanismos de control tradicionales de la OIT. Aunque está enfocada, ante todo, a los Estados Miembros, a quienes se invita a adoptar medidas de implementación, puede con facilidad, y precisamente porque está redactada de modo general, servir como una referencia directa para los nuevos actores globales sociales. En particular, ha servido como inspiración para las empresas multinacionales, cuando proyectan sus códigos de conducta social, o definen los criterios que deben observar los informes sociales o auditorías. Las iniciativas privadas suplementan así a la ley nacional en esos puntos o, lo que sucede más a menudo, aseguran un mayor respeto por ella.

\section{ONU: El Pacto mundial y los Principios Rectores sobre las Empresas y los Derechos Humanos.}

Las Naciones Unidas han elaborado más de una iniciativa para involucrar a las grandes compañías nacionales y transnacionales en la defensa de los tratados universales de derechos humanos. Ha lanzado un Pacto mundial («Global compact»), en julio de 2000, junto con varias otras organizaciones internacionales, incluso la OIT. Instrumento puramente voluntario, pide a las empresas que hagan suyos, apoyen y lleven a la práctica una serie de valores fundamentales en materia de derechos humanos, normas laborales, medio ambiente y lucha contra la corrupción. Insiste sobre diez principios, de los cuales cuatro proceden de la Declaración ya mencionada de la OIT, adoptada en 1998, y de los convenios correspondientes. 
Las empresas que se adhieren al pacto tienen un compromiso individual de trabajar en la aplicación de los diez principios. El documento cuenta con un conjunto de recursos y herramientas que proporcionan orientación a las empresas cuando deben tomar decisiones relacionadas con los principios. Una de las opciones se encuentra en un modelo preparado, a fin de concretar su visión en términos de resultados. Ofrece a sus participantes diversas oportunidades para involucrarse en actividades que maximicen los beneficios y el valor de la participación (proyectos de colaboración; redes nacionales; reuniones y talleres en diferentes países; puesta en común de experiencias; acciones conjuntas).

Para no ser excluidas de la lista de los participantes al Pacto, las empresas deben suministrar regularmente comunicaciones sobre los progresos. Los informes deben contener una confirmación de la adhesión a los principios referidos, una descripción de los medios concretos que han adoptado para ponerlos en práctica y una medida de los resultados obtenidos y esperados; se sugieren ciertos indicadores de realización.

Se considera como un factor importante de progreso la implicación de participantes exteriores. Entre ellos, se mencionan los representantes de la sociedad civil, de las organizaciones profesionales, de los gobiernos y de las instituciones internacionales y de las universidades. Pueden llevar conocimientos y experiencias, dar consejos, pedir explicaciones, estimular ciertas actividades

En breve, el Pacto se ha convertido en un foro amplio que favorece el aprendizaje y el diálogo en materia de responsabilidad social empresarial.

Los Principios Rectores sobre las Empresas y los Derechos Humanos, preparados por J. Ruggie y hechos suyos por el Consejo de Derechos Humanos de la ONU, en su resolución $17 / 4$, de 16 de junio de $2011^{9}$, van más allá. Proponen normas globales para tratar de las consecuencias negativas de las actividades empresariales sobre los seres humanos ${ }^{10}$. Según los puntos 13 y 19, la responsabilidad de respetar los derechos humanos exige que las empresas eviten que sus propias actividades provoquen o contribuyan a provocar consecuencias negativas sobre los derechos humanos, y hagan frente a esas consecuencias cuando se produzcan. Deben tratar de prevenir o mitigar los efectos perjudiciales directamente relacionados con operaciones, productos o servicios prestados por sus relaciones comerciales, incluso si no han contribuido a generarlos.

En estos casos, la empresa debe tomar las medidas necesarias para poner fin o prevenir esa situación, y ejercer su influencia para mitigar en la mayor medida posible otras consecuencias dañinas. Se considera que tiene influencia la empresa que sea capaz de modificar las prácticas perjudiciales de una entidad que provoque un daño. Deberían

\footnotetext{
${ }^{9}$ Estos principios los ha apoyado una recomendación CM/Rec (2016)3 del Comité de Ministros del Consejo de Europa del 2 de marzo de 2016.

${ }^{10}$ Véase, en particular, HECKENDORN URSCHELER, Lukas, FOURNIER, Johanna (Dir.), Regulating Human Rights Due Diligence for Corporations, Ginebra, Schulthess, 2017; ALSTON, Philip, GOODMAN, Ryan, International Human Rights, Oxford, Oxford University Press, 2013; BLACHER, Lara, "Codes of Conduct: The Trojan Horse of International Human Rights Law?”, Comp. Labour Law \& Pol. Journal, spring 2017, vol. 38, $\mathrm{n}^{\mathrm{o}} 3$, p. 468 y ss.
} 
actuar así teniendo en cuenta su parte de responsabilidad y usar de su poder de influencia - leverage en el texto original inglés - para atenuar, en la medida de lo posible, todo efecto negativo entre sus relaciones comerciales. Un proyecto de tratado vinculante sobre el tema se discute en las Naciones Unidas.

El punto 13 hace eco a las líneas directrices de la OCDE sobre las multinacionales, especialmente al párrafo 13 de los principios generales, a los cuales ya me referí, y que conciernen más específicamente a las cuestiones laborales. La ley núm. 2017-399, de 27 de marzo de 2017, introduce el deber de vigilancia en la legislación francesa.

\section{Iniciativas del Banco mundial y de su grupo.}

En 2016, el Directorio Ejecutivo del Banco Mundial aprobó un nuevo Marco Ambiental y Social (MAS) para ayudar a proteger a las personas y el medio ambiente en los proyectos de inversión que financia. Este esfuerzo forma parte de un conjunto de iniciativas clave, incluidas la reforma en adquisiciones y las estrategias climática y de género, recientemente llevadas a cabo por el Banco para mejorar los resultados en términos de desarrollo. Los resguardos adicionales incluidos en el marco, que sientan un precedente dentro del Banco Mundial, incluyen medidas detalladas de protección del trabajo. También subraya la responsabilidad de incluir la participación de la parte interesada a lo largo del ciclo del proyecto, y un principio de no discriminación, potenciado por una nueva Directiva Obligatoria del Banco Mundial, que hace una lista de grupos vulnerables y desfavorecidos y exige al personal que ayude al prestatario a considerar, mitigar y gestionar posibles asuntos relacionados.

La Corporación Financiera Internacional (International Finance Corporation, IFC), la sociedad financiera internacional del grupo del Banco mundial, ha elaborado medios para facilitar la promoción de la empresa ciudadana y ayudar a sus clientes y al sector privado en los países emergentes a identificar posibilidades de inversión que corresponden a este objetivo. Sus normas de desempeño ("performance standards") en materia de sostenibilidad social y medioambiental, adoptada en 2012, reconocen que el crecimiento económico a través de la creación de empleo y de ingresos debe acompañarse de la protección de los derechos fundamentales de los trabajadores. Los requisitos establecidos se inspiran, en particular, en los instrumentos de la OIT y cubren, además de los derechos fundamentales, la relaciones laborales, el respeto de la legislación nacional, la protección de las categorías más vulnerables de trabajadores (niños, migrantes, trabajadores contratados por un tercero, trabajadores de una cadena de suministros ${ }^{11}$ ), la promoción de la salud y de la seguridad en el trabajo ${ }^{12}$

\section{E. Iniciativas europeas.}

Al igual que otras instituciones, la Unión europea utiliza varios medios para crear condiciones favorables para un crecimiento sostenible, un comportamiento responsable de las empresas y la creación de empleo duradero a medio y largo plazo. En una

\footnotetext{
${ }^{11}$ SANGUINETI RAYMOND, Wilfredo, op. cit.

${ }^{12}$ IFC, IFC Performance Standards on Environmental and Social Sustainability, Washington, 2012.
} 
comunicación de 2011 al Parlamento Europeo, al Consejo, al Comité económico y social y al Comité de las regiones, la Comisión detalla la estrategia de la UE al respecto para los años 2011-2014 ${ }^{13}$. El programa contiene compromisos de la propia Comisión para promover este tipo de iniciativas, así como sugerencias para las empresas, los Estados miembros y otros grupos interesados. Al aplicarlo, la Comisión tiene en cuenta las características particulares de las PYME, especialmente sus limitados recursos, y evita la creación de cargas administrativas innecesarias.

Por su parte, las organizaciones europeas de empresarios y de trabajadores del sector de la restauración han firmado, en enero de 2007, un convenio colectivo sobre la responsabilidad social de las empresas. El acuerdo establece una serie de normas mínimas voluntarias, que se conciben como una fuente de inspiración y una base para discusiones posteriores, y que alientan a las asociaciones nacionales del sector y a sus miembros a elaborar códigos de conducta u otras iniciativas parecidas, con la participación de los representantes del personal y de los sindicatos. Cubre las cuestiones siguientes: derechos fundamentales, formación, salud y seguridad, seguridad alimentaria, diálogo social, igualdad de oportunidades y ausencia de discriminación, condiciones de empleo y organización del trabajo, salario decente, métodos para la adjudicación de contractos de restauración, reestructuración, relaciones de negocio y elección de los proveedores, lucha contra la obesidad. Las susodichas organizaciones deben invitar a sus miembros que difundan y discutan el acuerdo a nivel nacional y les informen de ejemplos de buenas prácticas, que se analizarán para asegurar su seguimiento. El convenio colectivo cubre unos 600.000 trabajadores en Europa.

\section{F. Iniciativas nacionales.}

Bélgica, Canadá, Dinamarca y Francia, entre otros Estados, han adoptado medidas para promover una forma u otra de responsabilidad social de empresas. En los sitios respectivos sobre la responsabilidad social corporativa, figuran informaciones al respecto.

España cuenta con el Consejo Estatal de Responsabilidad Social de las Empresas (CERSE), órgano asesor y consultivo adscrito al Ministerio de Empleo y Seguridad Social, encargado de las políticas públicas de impulso y fomento de la RSE. Su creación responde al objetivo de agrupar en el mismo órgano a representantes de los distintos grupos de interés vinculados al tema. Los servicios del Ministerio ostentan la presidencia y la secretaría del Consejo, ejercen las labores de preparación, apoyo técnico y gestión, promueven este tipo de iniciativas, en particular para las pequeñas y medianas (PYMES), así realizan el diseño, gestión y seguimiento de programas y ayudas para su difusión y fomento.

\footnotetext{
${ }^{13}$ COM/2011/0681 final; WILLIAMSON, Naomi, STAMPE-KNIPPEL, Astrid, WEBER, Tina, Corporate Social Responsibility. National Public Policies in the European Union. Compendium 2014, Luxemburgo, EU Publications Office, 2014.
} 


\subsection{Normas de gestión.}

Los diferentes grupos que elaboran códigos de conducta también redactan «normas» de gestión («management framework»). En términos generales, estas disposiciones animan a las empresas a adoptar métodos de gestión propicios para evaluar sus actividades en lo que concierne a su responsabilidad social. Son de varios tipos ${ }^{14}$.

\section{A. Etiquetado social.}

El "sello social" constituye una forma de comunicar informaciones sobre las condiciones sociales en que se desarrolla la fabricación de un producto o la prestación de un servicio. Algunas veces figura en el objeto o su embalaje. Otras veces lo exponen los comercios en su tienda o su escaparate. Se dirige a los consumidores o a los colaboradores comerciales; corresponden a una lógica de mercado.

Si una empresa, uno de sus productos o de sus servicios, adquiere una cierta notoriedad basada en su código de conducta, su nombre o su marca constituyen una denominación de gran valor. Puede suceder incluso que conceda la explotación de la misma, a través de una licencia, a subcontratistas, franquiciados y concesionarios que cumplen criterios preestablecidos ${ }^{15}$.

En cambio, otros etiquetados proceden de autoridades o instituciones independientes, que los elaboran y controlan. Son asociaciones empresariales que garantizan el respeto de un código de conducta, sindicatos que responden de esta manera de la buena aplicación de un programa social, ONG u otras agrupaciones que certifican la implementación correcta, por parte de la firma beneficiaria, de una política conforme a indicadores seleccionados, incluso a falta de un código de conducta.

\section{B. Programas de acreditación y de certificación.}

Los programas de acreditación y de certificación constituyen hoy día prácticas corrientes. La mayoría los administra una institución principal, que aprueban otros organismos, como agencias de calificación. Se encuentran numerosos ejemplos en sectores variados, tales como el textil, calzado, industria ligera, alfombras, fabricación de juguetes, turismo, agricultura, agroalimentario, o industria forestal. Los programas se apoyan en criterios o normas de carácter privado, que se refieren, entre otros elementos, a las relaciones laborales y a las condiciones de trabajo. A veces, y como han puesto de manifiesto informes de la OIT, se refieren a los instrumentos de la Organización, incluso a su Declaración de 1998, aunque lo hacen en una forma selectiva. Las normas cuya observancia ha resultado más frecuentemente controlada se refieren a la ausencia de discriminación, de trabajo forzoso o infantil, la libertad de asociación y la negociación

\footnotetext{
${ }^{14}$ MALECKI, Catherine, op. cit.

${ }^{15}$ DILLER, Janelle, “¿Una conciencia social en el mercado mundial?: Dimensiones laborales de los códigos de conducta, el etiquetado social y iniciativas de los inversores”, Revista Internacional del Trabajo, 1999, vol. $18, n^{\circ} 2$.
} 
colectiva, el acoso y el comportamiento abusivo, la seguridad y la salud en el trabajo, los salarios y las prestaciones sociales, los horarios de trabajo ${ }^{16}$. No obstante, faltan informaciones recientes a nivel global.

Las inspecciones y auditorias las organizan grandes despachos internacionales de contables acreditados y de consultores, oficinas de una talla menor, empresas especializadas en el control de la calidad, universitarios, sindicatos, ONG, establecidos en naciones industrializadas o no, pudiendo participar varios, de forma conjunta, en la supervisión. La mayoría de las veces, las investigaciones se realizan a través de visitas sobre el terreno, incluyendo un examen de los documentos de la empresa, entrevistas con sus dirigentes, el personal y su delegados, incluso posiblemente con representantes de la sociedad civil. A veces, comprenden discusiones con grupos informales, así como una evaluación de los riesgos a que se exponen los trabajadores en materia de seguridad y salud laboral. Sin embargo, en muchos casos, los métodos de vigilancia adoptados parecen que se hallan aún en una fase de elaboración muy preliminar.

\section{Informes sociales.}

La preparación de informes sobre las repercusiones sociales y medioambientales de sus actividades constituye otra iniciativa bastante habitual hoy en muchas empresas multinacionales, e incluso nacionales. La "Global Reporting Initiative” (GRI) parece haber creado el sistema más conocido ${ }^{17}$. Intenta mejorar la posibilidad de comparar y la credibilidad de este tipo de documentos. Han participado en su concepción empresas, incluso despachos de contables acreditados, sindicatos, organizaciones no gubernamentales, asociaciones ecologistas o de defensa de los derechos humanos. Tiene como objetivo establecer normas ampliamente aceptadas y reconocidas, análogas a las reglas elegidas para la preparación de los informes financieros.

El sistema GRI contiene indicadores relativos a las condiciones de empleo en el apartado "Indicadores de rendimientos sociales: prácticas en materia de relaciones laborales y trabajo decente”. La referencia al trabajo decente se remite a los trabajos de la OIT, que, como se sabe, utiliza el concepto para expresar la síntesis de sus actividades y la coordinación de sus objetivos estratégicos ${ }^{18}$. Las herramientas de evaluación se refieren al empleo, las relaciones colectivas, la higiene y la seguridad en el trabajo, la formación, la diversidad y la igualdad de oportunidades. Hacen referencia a la Declaración de principios tripartita de la OIT sobre las empresas internacionales y la política social, así como a las directrices de la OCDE dedicadas a las empresas multinacionales. El sistema contiene otros indicadores, con el título "Indicadores de rendimientos sociales: derechos humanos”, que mencionan los convenios fundamentales de la OIT y la Declaración universal de los derechos humanos.

Conviene destacar que se refieren tan solo a estos documentos, y no a otros, adoptados por las Naciones Unidas, que tienen una fuerza obligatoria a partir de la ratificación, en

${ }^{16}$ OIT, Documento GB.288/WP/SDG/3, Ginebra, OIT, 2003, §§ 9-13,.

${ }^{17}$ https://www.globalreporting.org

${ }^{18}$ https://g4.globalreporting.org/specific-standard-disclosures/social/labor-practices-and-decent-work 
particular a los dos pactos de 1966 sobre los derechos civiles y políticos por un lado, y de los derechos económicos, sociales y culturales, por otro. Sin embargo, merece la pena precisar que los indicadores se refieren a la ausencia de discriminación, a la libertad de asociación y a la negociación colectiva, a la abolición del trabajo forzoso e infantil, a las prácticas disciplinarias, a las medidas de seguridad, así como a los derechos de las poblaciones locales. Mencionan los convenios de la OIT núm. 29, sobre el trabajo forzoso; núm. 138, sobre la edad mínima, y el repertorio de recomendaciones prácticas de la Organización sobre los sistemas de gestión de la seguridad y de la salud en el trabajo.

De todos modos, algunos de los elementos que trata de medir el GRI son difíciles de cuantificar y, por consiguiente, las conclusiones pueden carecer de significación.

\section{Inversiones socialmente responsables.}

La ética social de inversiones intenta favorecer las buenas políticas sociales de las empresas, utilizando las herramientas financieras tradicionales, como el establecimiento de índices y las técnicas de la calificación, mientras preservan el rendimiento económico de las aportaciones. Utiliza dos medios principales de acción ${ }^{19}$. El primero consiste en la facultad para los inversores de tener en cuenta las realizaciones sociales en la constitución de su cartera de valores; comprarán ciertos títulos, basándose en los criterios o las normas que han seleccionado, y no comprarán otros. El segundo medio aprovecha la posibilidad que ofrece a los accionistas de ejercer sus derechos para influenciar la política de la empresa. Por consiguiente, estos medios se utilizan en momentos y en sentidos diferentes: el primero, antes de la compra de valores, o decidiendo cambiarlos; el segundo, después de la entrada en el capital de la empresa. Los fondos de pensiones de la función pública $\mathrm{y}$ de las instituciones religiosas se muestran particularmente activos al respecto ${ }^{20}$.

Los criterios y las normas seleccionados para decidirse por una inversión no parecen más precisos o uniformes que en las demás iniciativas precedentes. No obstante, algunas cuadrículas de lectura recurren al conjunto de las normas internacionales del trabajo: Calvert, Coreratings, EIRIS (Ethical Investment Research Service), PIRC (Pensions and Investment Research Consultants Ltd.) y Vigeo/ARESE. Otra agencia de calificación, la SAM, pide a las empresas si suscriben públicamente la Declaración de la OIT sobre las multinacionales; otras, como la KLD, repiten los puntos que cubren las normas fundamentales de la $\mathrm{OIT}^{21}$.

\section{Códigos operacionales.}

Contrariamente a los precedentes, los códigos operacionales contienen un compromiso de las empresas, y posiblemente de otras partes, de adoptar una cierta conducta. Una

\footnotetext{
${ }^{19}$ DILLER, Janelle, op. cit.; CLARK, Gordon L., HEBB, Tessa, "Pension Fund Corporate Engagement: the fifth stage of capitalism”, Relations industrielles/Industrial Relations, invierno 2004, vol. 59, n 1, pp. 142-171.

20 DILLER, Janelle, op. cit.

${ }^{21}$ BALLESTERO, Enrique, PÉREZ-GLADISH, Blanca, GARCIA-BERNABEU, Ana Maria, Socially Responsible Investment. A Multi-criteria Decision Making Approach, Heidelberg, Springer, 2015; OIT, Documento GB.288/WP/SDG/3, Ginebra, OIT, 2003, § 20.
} 
antigua nota informativa de la OIT sobre su contenido revelaba que parecían poco frecuentes las referencias a las normas fundamentales del trabajo ${ }^{22}$. En lo que hace al trabajo, los documentos trataban más de la protección de la salud, o del cálculo de los salarios, basándose, según el caso, en la legislación nacional, las reglas sectoriales, o una fórmula propia. Cuando la iniciativa procedía de varias partes interesadas (sindicatos, asociaciones industriales o de empresas, ONG), se mencionaban más a menudo las disposiciones fundamentales.

Sea cual sea el nombre, el código de conducta contiene compromisos que una empresa asume voluntariamente, es decir, sin estar jurídicamente obligada a hacerlo. El documento puede tener la forma de acuerdos "marco" firmados junto con un sindicato. Puede resultar también de un acuerdo con otras organizaciones no gubernamentales. Sin embargo, en la mayoría de los casos, se analiza como una decisión unilateral de la empresa, una declaración pública, o un añadido por parte de la dirección al reglamento de empresa.

Ciertos códigos solo se refieren a las actividades de una empresa, sea dentro de un país, sea incluso en el extranjero. Otros afectan también a los colaboradores comerciales, sobre todo los proveedores y los subcontratistas. Muchos documentos adoptados por iniciativa de varias partes interesan únicamente a las relaciones con los proveedores y los subcontratistas; la mayoría de los debates sobre el control de las prácticas de trabajo se concentran sobre este tipo de acción. Su formulación no siempre permite saber si los códigos que rigen las cadenas de suministro contienen, en realidad, un modo de regulación totalmente nuevo, o solo intentan consolidar el respeto de disposiciones jurídicas en vigor.

\section{Límites de la regulación actual.}

Frente a la mundialización, aparecen señales de desagregación del derecho. Ya he subrayado que existe una tendencia, en particular en el derecho transnacional del trabajo, a multiplicar los procedimientos, las técnicas, las instancias de control. En el cruce del derecho internacional público y de las iniciativas de derecho privado de tipo RSE, resulta un conjunto complejo de interacciones horizontales y verticales. Aumenta la confusión la distinción entre el soft law y la hard law, al poder emplearse, cada uno de estos adjetivos, en varios sentidos ${ }^{23}$.

Algunos se preguntan sobre la posibilidad de votar nuevas normas internacionales para crear un cuadro jurídico transnacional sistémico. Más allá de las dificultades para definir su contenido e implementar procedimientos de control, ninguna organización supranacional tiene, en el estado presente del concierto de la Naciones, un poder suficiente para imponer a las multinacionales que las apliquen. Las violaciones sólo son

22 Véase OIT, Codes of conduct and multinational enterprises (CD-ROM), Ginebra, 2001; www.ilo.org/basi; GÖKHAN KOÇER, Rüya, FRANSEN, Luc, "Codes of Conduct and the Promise of a Change of Climate in Workers Organizations", European Journal of Industrial Relations, 2009, vol. 15, $\mathrm{n}^{\circ}$ 3, pp. 237-256.

${ }^{23}$ DELMAS-MARTY, Mireille, "Où va le droit ? Entre pot au noir et pilotage automatique, le droit peut-il nous guider vers une mondialité apaisée ?”, La semaine juridique, abril 2018, nº 14, pp. 679-680. 
pasibles de las sanciones previstas por los derechos nacionales, y no por convenios internacionales, estos últimos creando hasta ahora obligaciones para los Estados o las organizaciones internacionales, y no para las personas físicas o jurídicas privadas. Parece más realista reconocer los límites estratégicos (1) y técnicos (2) de las reglas adoptadas por las multinacionales así como las incertidumbres de su valor jurídica y de su supervisión (3), y después razonar a partir de esta comprobación (4).

\section{Límites estratégicos de las reglas de RSE.}

Los compromisos aceptados traducen una política y unos objetivos definidos por la dirección de la empresa, o al menos determinados con su aprobación, lo que conduce a limitaciones importantes ${ }^{24}$. Las opciones elegidas se basan en criterios empresariales, que no se corresponden necesariamente con los fines de una Organización tripartita como la OIT.

La RSE se refiere a una empresa singular y, en su caso, sus socios comerciales, las entidades que participan en su cadena de valor, o que se relacionan directamente con sus operaciones comerciales, productos o servicios. Se enfoca sobre los elementos donde concurren los intereses de sus trabajadores y los suyos. Se incluyen rara vez otras cuestiones en que divergen las preocupaciones de la dirección y de su personal, como la precariedad del empleo. Además, las políticas sociales sobrepasan en muchos puntos el ámbito de la empresa, cualquiera que sea su dimensión, en lo que respecta, por ejemplo, a la creación de empleo o a la formación profesional; se discuten a un nivel más general, aunque algunas veces las empresas manifiestan el deseo de participar en programas de inserción o de vuelta al mercado de trabajo. Sin embargo, incluso, en estos últimos casos, no tratan - no es su papel - los problemas sociales generales de una comunidad local, o de un país.

También es desigual la difusión de estas prácticas sociales de las empresas. Afectan más a las grandes empresas, que a las Pymes, mientras que las últimas siguen sirviendo de principal fuente de empleo. Además, las grandes compañías que adoptan políticas dinámicas de desarrollo de los recursos humanos, a través de buenas condiciones de trabajo, buscan, de esa forma, una ventaja comparada frente a competidores activos; no están necesariamente dispuestas a favorecer la imitación, por otras empresas, de las medidas adoptadas. El hecho explica los llamamientos para una mayor transparencia lanzados por la Unión Europea, y las dificultades para seguirlos ${ }^{25}$.

Algunas empresas están más dispuestas, o son más capaces que otras, a aceptar una responsabilidad social. En cambio, existe un riesgo que sus estrategias contradigan los esfuerzos de los Estados para mejorar el régimen de trabajo, estimular la creación de empleos, liberalizar los intercambios y distribuir equitativamente los frutos del

\footnotetext{
${ }^{24}$ Véase también PÄRLI, Kurt, VÖGTLI, Jasmin, "Control and Sanction of Employees on the Basis of Codes of Conduct - A Question of Basic Labour (Human) Rights?”, Labor Law Journal, 2020, vol. 71, $\mathrm{n}^{\circ}$ 1, pp. 71- 84.

${ }^{25}$ La falta de transparencia puede tener otras causas y otros efectos; en estos casos hay que hacerse preguntas sobre el valor de las políticas efectivamente aplicadas.
} 
crecimiento $^{26}$. Y, lo que es aún más grave, cabe temer que, a veces, medidas que se elaboran en los países industrializados, sin consultar con las filiales o los subcontratistas en las Naciones del Sur, no manifiesten un entendimiento suficiente de los problemas de la pobreza y la disparidad cultural.

\section{Límites técnicos de la RSE.}

Los límites técnicos se refieren a su contenido. Algunos códigos de conducta enuncian normas propias, o mencionan instrumentos internacionales específicos, incluso convenios o recomendaciones internacionales del trabajo. Otros se limitan a principios generales. para los cuales queda poco clara la manera de ponerlos en práctica ${ }^{27}$. Ninguno, que yo sepa, se refiere al conjunto de las normas de la OIT, o a las que la Organización considera al día. Las reglas seleccionadas varían según los riesgos y las preocupaciones de cada empresa, sin aspirar a la universalidad. Normalmente, los documentos que expresan un acuerdo con una o más confederaciones sindicales contienen una dimensión social más marcada.

Los límites técnicos afectan también a su campo de aplicación, restringido a una o varias empresas, y a la duración de su validez. En todo caso, la adopción de estas iniciativas no permite a las empresas eximirse de la aplicación de la ley del país de acogida, incluso de los convenios internacionales integrados en su orden jurídico. Desde luego, resulta impensable tratar de implementar, con tales métodos, el derecho nacional o internacional del trabajo.

\section{Implementación de las reglas privadas de trabajo.}

\section{a) Efectos jurídicos.}

Caso por caso, se necesita determinar las reglas aplicables. Cuando la empresa posee establecimientos en más de un país, el régimen legal de un contrato o de un acuerdo colectivo depende de la ley, o de las leyes aplicables, cuestión de derecho internacional privado, o, llegado el caso, del derecho europeo. Se determinan después las reglas aplicables que provienen de la legislación, sea laboral (por ejemplo, sobre el reglamento interior), sea mercantil (sobre el régimen de las empresas o sobre la competencia desleal), sea civil.

Constatamos que el valor jurídico del compromiso empresarial varía considerablemente. Si la regla jurídica se define por referencia a la coacción, se puede considerar que impone una conducta bajo la amenaza de una sanción en caso de violación. En cambio, las otras técnicas de implementación de políticas sociales recurren principalmente a la razón y a la

\footnotetext{
${ }^{26}$ KOLBEN, Kevin, "Transnational Labor Regulation and the Limits of Governance”, Theoretical Inquiries in Law, julio 2011, vol. 12, $\mathrm{n}^{\circ}$ 2; DILLER, Janelle, op. cit.

${ }^{27}$ ROSENBAUM RIMOLO, Jorge, "Negociación colectiva internacional. El impulso y sus frenos en Latinoamérica”, XXII Congreso mundial de derecho del trabajo y de la seguridad social (Turín, 4-7 de septiembre 2018), http://www.islssltorino2018.org/papers/
} 
persuasión. Estas últimas incluyen la conclusión de declaraciones, la adopción de medidas económicas, la organización de campañas de formación y de información, así como la elaboración de "normas” técnicas (pero no jurídicas) y de directrices prácticas. Pueden realizarse sin que se utilicen medidas con alcance jurídico. Observarlo no significa que se desprecia la utilidad de tales acciones y declaraciones, su capacidad de convencer.

A veces, las reglas sociales transnacionales se limitan a inspirar la política de recursos humanos de las empresas. Otras veces poseen un real valor imperativo, aunque no es fácil descubrirlo ${ }^{28}$. Algunas empresas se obligan a respectar condiciones mínimas de trabajo, ya sea en un convenio colectivo con un sindicato o una ONG, ya sea, más frecuentemente, en un documento que adquiere la forma jurídica de acto unilateral, declaración pública o añadido al reglamento de empresa, ya sea en contratos, de naturaleza privada, que concluyen con sus proveedores, subcontratistas, concesionarios o clientes. Los “códigos” integran los compromisos que asumen las empresas sobre una base puramente voluntaria.

Los instrumentos unilaterales de la compañía no tienen efectos jurídicos claros. En muchos casos, puede considerarse que no son legalmente obligatorios, porque la dirección no tenía la intención cierta de obligarse; en otros, no es clara la regla aplicable. Tampoco es fácil aportar la prueba del contenido legal preciso de la obligación. Sin embargo, cada vez, los jueces condenan a las empresas que no respetan su código de conducta apoyándose en figuras jurídicas bien conocidas. En efecto, las legislaciones civiles que se inspiran en el código Napoleón reconocen efectos jurídicos al compromiso unilateral; otras consideran que se integra como una cláusula implícita en los contratos de trabajo que no lo contradicen (Reino Unido); en los Estados Unidos, los tribunales admiten la responsabilidad civil, no contractual, sino delictual por dolo de la empresa por declaración pública engañosa.

Cabe notar que el empresario puede tener una responsabilidad jurídica previa al código de conducta, como en materia de disturbios en la vecindad, de accidentes de trabajo y enfermedades profesionales, o de discriminación en el empleo. El documento pone en práctica una obligación legal preexistente.

Algunas veces, puede invocarse el derecho mercantil. La directiva europea núm. 2005/29 de 11 de mayo de 2005, relativa a las prácticas comerciales desleales de las empresas en sus relaciones con los consumidores en el mercado interior, considera engañosa una práctica comercial que pueda inducir a error al consumidor medio, y que pueda hacerle tomar una decisión sobre una transacción que, de otro modo, no hubiera tomado. Supone, en particular, el incumplimiento por parte del comerciante de compromisos incluidos en códigos de conducta que aquel se haya obligado a respetar de una manera firme y comprobable.

${ }^{28}$ Hay que verificar su "grado de intensidad normativa” (“degré d'intensité normative”), por citar a MAZUYER, Emmanuelle, "La force normative des instruments adoptés dans le cadre de la responsabilité sociales de l'entreprise”, en THIBIERGE, Catherine et al., La force normative. Naissance d'un concept, París, LGDJ, 2009, p. 577. Véase también, DE QUENAUDON, René, MARTIN-CHENUT, Kathia, La RSE saisie par le droit. Perspectives interne et internationale, París, Pedone, 2016. 
También la directiva núm. 2014/95 de 22 de octubre de 2014, sobre la divulgación de información no financiera e información sobre diversidad por parte de determinadas grandes empresas y determinados grupos, exige que las grandes firmas incluyan en el informe de gestión un estado no financiero que contenga información relativa, como mínimo, a cuestiones medioambientales y sociales, así como relativas al personal, al respeto de los derechos humanos, a la lucha contra la corrupción y el soborno. Debe incorporar una descripción de las políticas que aplica la empresa en relación con dichas cuestiones, que incluya los procedimientos de diligencia debida aplicados ${ }^{29}$.

\section{b) Supervisión.}

La credibilidad de las reglas aplicadas por las empresas depende de los controles efectuados para verificar la aplicación efectiva de los compromisos asumidos. La vía judicial y la imposición de sanciones legales se limitan a los compromisos que tienen un valor jurídico. En su ausencia, existen métodos de evaluación y de seguimiento, cuya existencia y seriedad conviene verificar ${ }^{30}$.

Los acuerdos concluidos entre empresas multinacionales y federaciones sindicales crean, en principio, procedimientos de supervisión. Constituyen, en su mayoría, mecanismos de concertación, de sensibilización y de quejas que prolongan a nivel global las instituciones de relaciones laborales establecidas tradicionalmente en los niveles nacional, sectorial y de empresa. Estos convenios colectivos transnacionales prevén que los dirigentes de la empresa, los ejecutivos y los representantes de los trabajadores se reúnan para examinar su implementación. A veces, imponen obligaciones más específicas: difundir el acuerdo y, llegado el caso, traducirlo; elaborar programas conjuntos de formación, etc. A menudo, el control del respeto de sus disposiciones corresponde, en primer lugar, a los responsables locales de la empresa y de los sindicatos; si surgen dificultades, existen procedimientos de solución a niveles más altos. Frecuentemente, los acuerdos mencionan el convenio núm. 135 de la OIT, relativo a los representantes de los trabajadores, $1971^{31}$.

Los códigos de conducta que se elaboran de otra forma organizan también, cada vez más, mecanismos de vigilancia, internos o externos, en los que los segundos completan muchas veces los primeros. Sin embargo, los procedimientos de verificación, incluso los que se dirigen por organismos exteriores a la empresa, suscitan problemas complejos. Se refieren a la competencia y a la independencia de los inspectores que provienen de instituciones privadas, elegidas y pagadas por la empresa, así como a la duración y al objeto de las auditorias. Tratan también, como ya he subrayado, del carácter más o menos preciso y verificable de las cláusulas que contienen los documentos ${ }^{32}$.

\footnotetext{
${ }^{29}$ BORELLI, Silvia, "La legislation européenne contre les discriminations et le devoir de diligence des EMN”, Revue de droit compare du travail et de la sécurité sociale, 2018, nº 1, pp. 64-65.

30 HODGES, Christopher, Law and Corporate Behaviour. Integrating Theories of Regulation, Enforcement, Compliance and Ethics, Oxford, Hart Publishing, 2015; KUN, Attila, "How to Operationalize Open Norms in Hard and Soft Laws: Reflections Based on Two Distinct Regulatory Examples", International Journal of Comparative Labour Law and Industrial Relations, 2018, vol. 34, n ${ }^{\circ}$ 1, pp. 23-51. ${ }^{31}$ Véase documento GB.288/WP/SDG/3, op. cit., §§ 15-17.

${ }^{32}$ Véase POSNER, Michael, NOLAN, Justine, "Can Codes of conduct play a role in promoting workers rights?”, en GOULD, William B., FLANAGAN, J. (Dir.), International labor standards. Globalization,
} 
A menudo, las normas de gestión se acercan a las reglas de calidad y de medio ambiente que se encuentran en el modelo ISO. En el campo social, la norma ISO precisa las medidas preventivas y correctivas que hay que adoptar, favorece la mejora permanente, se centra en los sistemas de tratamiento y de documentación que prueban la eficacia de los métodos elegidos, utilizando técnicas de auditoría. Constituye un ejemplo de esta concepción el modelo de gestión del Pacto Mundial de la ONU, que proporciona a las empresas orientación sobre la manera de evaluar los impactos de sus acciones ${ }^{33}$.

\section{Primeras conclusiones.}

Por consiguiente, estas disposiciones constituyen garantías útiles de los derechos de los trabajadores, complementan las legislaciones laborales, y que se han redactado especialmente en situaciones en las que el derecho del trabajo no cubre todas las categorías de trabajadores, o no se aplica suficientemente. La observación vale para muchos países y para las relaciones laborales internacionales. De igual modo, y aunque lo hacen de una manera limitada, los códigos de conducta contribuyen a la implementación de las normas de la OIT, en el sentido de que pueden concretar algunas disposiciones que adopta la Organización en las empresas de que se trate.

Por otro lado, la diversidad de esos documentos supone una debilidad, porque falta la coherencia en los principios que consagran. Otras limitaciones se refieren a su campo de aplicación. Las empresas que los adoptan operan esencialmente en los sectores estructurados, y no, en todo caso directamente, en la economía informal, donde trabaja un número considerable de personas de los países en vía de desarrollo; encontramos aquí otra razón para extender su efectividad a los subcontratistas, que utilizan a menudo la mano de obra desempleada que vive en las zonas más pobres de las ciudades y el campo. Las empresas más poderosas son las más dispuestas a seguir esta política para defender su imagen de marca, porque están también más afectadas por las campañas mediáticas hostiles ${ }^{34}$.

El estudio de las modalidades de los informes sociales evidencia que estas iniciativas suponen también complementos útiles a la acción normativa internacional, aunque no poseen un carácter coherente, sistemático y global, que les permitiría tener una influencia significativa y duradera en el nivel universal. Contribuye a mejorar la situación la decisión de países como Bélgica o Francia de imponer a las sociedades que tienen una cierta dimensión el deber de elaborar un informe sobre algunos aspectos de las condiciones de trabajo.

Trade and Public Policy, Stanford, California, Stanford University Press, 2003, pp. 208-216; BOIRAL, Olivier, "Certificar la buena conducta de las empresas. Retos problemas y perspectivas", Revista Internacional del trabajo, 2003, vol. 122, $\mathrm{n}^{\circ} 3$.

${ }^{33}$ BOISSON DE CHAZOURNES, Laurence, MAZUYER, Emmanuelle (Dir.), Le Pacte mondial des Nations-Unies 10 ans après, Bruselas, Bruylant, 2011.

${ }^{34}$ GOULD, William B., FLANAGAN, J. (Dir.), International labor standards. Globalization, Trade and Public Policy, Stanford, California, Stanford University Press, 2003, p. 10 
En términos generales, resulta problemático, en lo que mira a los aspectos laborales, la calidad metodológica de las evaluaciones de efectividad.

\section{Reflexiones finales para un futuro mejor.}

Parecen evidentes tanto la utilidad como las carencias de estas iniciativas ${ }^{35}$. La regulación transnacional que consagra la responsabilidad social de la empresa se presenta como un apoyo de la acción pública, la estimula y, si llega el caso, permite una mejor realización de sus objetivos.

Ofrece un marco regulador a las empresas multinacionales, aunque su valor jurídico es incierto, cuando no aparecen claramente la ley aplicable o las obligaciones internacionales del Estado de acogida. La incertidumbre proviene de la multiplicidad de países donde operan, o de las estructuras administrativas y legales débiles de los mismos. Observamos así cómo se desarrolla una dinámica de complementariedad entre las normas de la OIT y las políticas sociales de las grandes empresas nacionales e internacionales. Las últimas buscan consolidar la protección de los derechos laborales en un espacio jurídico "gris” u opaco.

Las reglas de la OIT no pueden respaldar pura y simplemente ordenamientos jurídicos desfallecientes, sobre todo por dos razones. En primer lugar, nada obliga a un Estado a ratificar un convenio internacional, es decir, a asumir el compromiso jurídico de respetar unas determinadas normas internacionales; a lo sumo, existe una excepción en materia de libertad sindical ${ }^{36}$. La segunda razón se relaciona con el carácter no obligatorio de las conclusiones de los comités de control de la OIT; si se constata una violación de las normas, su derecho no conoce un sistema de sanciones parecido al de los derechos del trabajo nacionales.

Más allá de estas observaciones, es posible identificar técnicas jurídicas cuya generalización permitiría ofrecer la seguridad de una mejor protección de los derechos laborales en las empresas multinacionales, y de hacerlo integrando el fenómeno desestabilizador de la globalización. Estas garantías no pueden aplicarse, de forma útil, en un solo país sometido a las presiones de los otros. Exigen una coordinación, e incluso una armonización, de los medios utilizados a nivel universal. No pueden dejarse tan solo a las empresas, cualquiera que sea su poder y compromiso social. Su objeto social es producir con provecho, no el bien común de los pueblos. He subrayado las limitaciones que resultan de eso.

\footnotetext{
35 Véase DELMAS, Baptiste, "Peut-on contraindre les entreprises françaises à respecter les droits fondamentaux au travail à l'étranger?”, Analyse et Documents économiques, octubre 2015, n ${ }^{\circ} 121$; DAUGAREILH, Isabelle (Dir.), Responsabilité sociale de l'entreprise et globalisation de l'économie, Bruselas, Bruylant, 2010; MAZUYER, Emmanuelle (Dir), Regards croisés sur le phénomène de la responsabilité sociale de l'entreprise, París, La documentation française, 2010.

${ }^{36}$ La Declaración de 1998 sobre principios y derechos fundamentales en el trabajo menciona también otros derechos "fundamentales", aunque solo exige a los Estados que no los han ratificado que presenten memorias anuales sobre los progresos realizados para respetar los principios que albergan.
} 
Los progresos al respecto requieren una movilización de los Estados, de las empresas y de las ONGs, incluidos los sindicatos, sobre estrategias comunes como la utilidad de inspirarse en el derecho de la responsabilidad y una mejor gobernanza en el uso de los modos de regulación.

La referencia en un número creciente de países a la responsabilidad compartida, solidaria o subsidiaria, ha permitido extender la protección de los trabajadores que, de una u otra manera, se relacionan con más de una entidad empresarial. En términos generales, constituye una respuesta a la fragmentación de las empresas, y a la separación que implica entre el poder y la responsabilidad ${ }^{37}$.

La ampliación de la responsabilidad del empresario no se limita a las relaciones individuales. Además, ciertas legislaciones, como la francesa, imponen a los empresarios obligaciones en términos de representación colectiva, incluso de negociaciones colectivas, al nivel de un grupo de empresas. Con un objetivo similar, algunos derechos han desarrollado nociones distintas, como la figura del co-empleador, con cualquier nombre. Los derechos norteamericanos han creado el concepto de empleador complejo, único u conjunto, que responde a preocupaciones cercanas ${ }^{38}$.

En fin, la responsabilidad de la empresa principal podría extenderse en la línea de los principios rectores sobre las empresas y los derechos humanos, propuestos por J. Ruggie $^{39}$. En este sentido, la ampliación de la responsabilidad corresponde a la idea de que la empresa, en la medida en que se aprovecha de la fuerza de trabajo, debe tener también obligaciones en beneficio del trabajador que ha permitido, de una manera u otra, un enriquecimiento.

El segundo punto se refiere a una mejor gobernanza en la manera de legislar. La proliferación de normas a que se ha hecho referencia da una impresión de desorden, y perjudica la efectividad. Sería deseable una mejor articulación de las reglas transnacionales obligatorias y de las disposiciones sin efecto vinculante de derecho privado y público, elaboradas por instituciones de distinta naturaleza.

También se vuelve más urgente regular de forma más clara y útil las relaciones y los conflictos laborales que sobrepasan las fronteras de un Estado ${ }^{40}$.

\footnotetext{
${ }^{37}$ Véase mi contribución SERVAIS, Jean-Michel, "España y las normas de la OIT o cómo renovar una bella historia”, en GIL Y GIL, José Luis (Dir.), España y la OIT. 100 años de diálogo en un mundo cambiante, Madrid, Ediciones Cinca, 2018, pp. 51-53.

${ }^{38}$ VERGE, Pierre (en colaboración con DUFOUR, Sophie), Configuration diversifiée de l'entreprise et droit du travail, Saint Nicolas, Québec, P U Laval, 2003; AUZERO, Gilles, "Coemploi: en finir avec les approximations", Revue de droit du travail, 2016, n ${ }^{\circ}$ 1, pp. 27-31.

39 Véase DROUIN, Renée-Claude, "Le développement du contentieux à l'encontre des entreprises multinationales: quel rôle pour le devoir de vigilance?”, Droit social, marzo de 2016, nº 3, pp. 246-255.

${ }^{40}$ Véase mi artículo "Droit international du travail et règlement des conflits transnationaux du travail", Revue de droit comparé du travail et de la sécurité sociale, 2014, nº 1, pp. 6-14.
} 
Incluso los reglamentos europeos núm. 593/2008, de 17 de junio de 2008, llamado "Roma I”41, y núm. 864/2007, de 11 de julio de 2007, llamado “Roma II”, que tienden a coordinar estas reglas, dejan sin soluciones precisas y satisfactorias los conflictos laborales en caso de relaciones colectivas de trabajo. El artículo 8 del primero se refiere tan solo a los contratos individuales de trabajo. Por consiguiente, se aplican a los convenios colectivos las disposiciones generales sobre los contratos de los artículos 3 y 19. Las partes deberían tener la opción de la ley aplicable. A falta de elección, se aplicará la ley del país donde tenga su residencia habitual el prestador del servicio, es decir, para una sociedad, asociación o persona jurídica, el lugar de su administración central. La solución corresponde al elemento identificado en su ámbito por algunas directivas sobre la información, la consulta o la participación del personal. Aunque resulta adecuado para los acuerdos de empresa o de grupo, no ofrece una solución para los conflictos colectivos, de derecho u de interés, que no acaban con un acuerdo.

El reglamento $n^{0} 864 / 2007$, relativo a la ley aplicable a las obligaciones extracontractuales, contiene solamente un artículo 9 que se refiere directamente a las relaciones laborales. Llega incluso a decir que la ley aplicable a la responsabilidad de una persona que tenga la condición de trabajador o de empresario, o de las organizaciones que representen sus intereses profesionales, por los daños causados por una acción de conflicto colectivo futura o realizada, será la ley del país en el que se haya emprendido la acción o vaya a emprenderse. No obstante, el artículo 4 añade que se aplicará la ley de dicho país, cuando la persona cuya responsabilidad se alega y la persona perjudicada tengan su residencia habitual en el mismo país en el momento en que se produzca el daño,

La norma especial del artículo 9 se entiende sin perjuicio de las condiciones relativas al ejercicio de esa acción, de acuerdo con la legislación nacional, y sin perjuicio de la situación legal de los sindicatos o de las organizaciones representativas de los trabajadores, según prevea la legislación nacional respectiva de los Estados miembros (28 ${ }^{\circ}$ considerando). Los principios tradicionales del derecho internacional privado permiten excepciones a esta norma, que podría limitar fuertemente el derecho de huelga: el Reglamento no afecta a la aplicación de las disposiciones de la ley del foro en aquellas situaciones que tengan carácter imperativo, cualquiera que sea la ley aplicable a la obligación extracontractual (artículo 16); puede excluirse la aplicación de una disposición de la ley designada, si esta aplicación es manifiestamente incompatible con el orden público del foro (artículo 26) ${ }^{42}$.

Esta evocación de las normas europeas, susceptibles de aplicarse en los conflictos de derecho, muestra que una solución legalista no es la más adaptada a las preocupaciones

\footnotetext{
${ }^{41}$ JO L.177 du 4.7. 2008, pp. 6-16. JAULT-SESEKE, Fabienne, "L'adoption du règlement nº 593/2008 (Rome I) sur la loi applicable aux obligations contractuelles: le choix de la continuité pour le contrat de travail”, Revue de Droit du Travail, oct. 2008, nº 10, p. 621.

${ }^{42}$ Véase también el artículo 17. Sobre las dificultades para interpretar este artículo, véase DORSSEMONT, Filip, VAN HOECK, Aukje, “Collective action in Labour conflicts under the Rome II Regulation”, Europe Labour Law Journal, 2011, vol. 2, $\mathrm{n}^{\circ} 1 \mathrm{y} \mathrm{n}^{\circ} 2$.
} 
de las partes globalizadas. Es más, ni siquiera existen disposiciones análogas para los conflictos de intereses.

Estos últimos no escapan totalmente de una reglamentación, ya que las reglas jurídicas imponen frecuentemente limitaciones a la forma que adopta el conflicto. No obstante, las normas actuales pueden acabar en la aplicación de varios derechos nacionales poco conciliables entre ellos. En efecto, las relaciones profesionales varían en una medida considerable de un Estado a otro. Las diferencias se refieren no solo a las reglas jurídicas aplicables, sino a la visión que se tiene del sistema y a la concepción que tienen de su misión los actores sociales ${ }^{43}$. El régimen de la huelga constituye un ejemplo significativo. Se analiza jurídicamente solo como una libertad en algunos países de Commonwealth, en el sentido que no implica una pena de multa o de prisión, sino que permite al empresario despedir al huelguista. Se considera como un derecho individual en otros Estados, o incluso colectivo, cuando solo los sindicatos pueden convocar una huelga legal. La reglamentación de la negociación colectiva también cambia de una legislación a otra. En particular, en muchos países, los acuerdos colectivos se aplican a todo el personal de la empresa, e incluso a toda la profesión, a través de diferentes técnicas; pero, en el Reino Unido, son simplemente un compromiso sobre el honor o un acuerdo entre caballeros ("gentleman agreement"). En el continente europeo, los sindicatos obtienen, en principio, su reconocimiento si responden a criterios de calidad de la representación; pero, en los Estados Unidos o en Canadá, por su alta lucha.

La complejidad en la solución de los conflictos colectivos transnacionales de trabajo exige claramente normas europeas e internacionales que ayuden a la solución pacífica de estos desacuerdos $y$, más específicamente, procedimientos extrajudiciales de conciliación, de mediación, incluso de arbitraje voluntario. Estas podrían integrarse en instrumentos de derecho heterónomo, convenio o tratado internacional, reglamento o directiva europea, como lo contemplan algunos. La conclusión de acuerdos marco, al nivel apropiado, por las confederaciones patronales y sindicales, o la elaboración en común de declaraciones, o, mejor aún, de recopilaciones de directrices prácticas, parecen una primera etapa útil ante las dificultades de encontrar un consenso político sobre una alternativa más ambiciosa.

\section{Bibliografía}

ALSTON, Philip, GOODMAN, Ryan, International Human Rights, Oxford, Oxford University Press, 2013.

AUZERO, Gilles, “Coemploi: en finir avec les approximations”, Revue de droit du travail, 2016, no 1.

\footnotetext{
${ }^{43}$ SERVAIS, Jean-Michel, "Labor Law and Cross-Border Cooperation among Unions", en GORDON, Michael, A., TURNER, Lowell (Dir.), Transnational Cooperation among Labor Unions, Ithaca, ILR Press, Cornell University Press, 2000, pp. 44-59.
} 
BALLESTERO, Enrique, PÉREZ-GLADISH, Blanca, GARCIA-BERNABEU, Ana Maria, Socially Responsible Investment. A Multi-criteria Decision Making Approach, Heidelberg, Springer, 2015.

BLACHER, Lara, "Codes of Conduct: The Trojan Horse of International Human Rights Law?”, Comp. Labour Law \& Pol. Journal, spring 2017, vol. 38, nº 3.

BOIRAL, Olivier, "Certificar la buena conducta de las empresas. Retos problemas y perspectivas”, Revista Internacional del trabajo, 2003, vol. 122, nº 3.

BOISSON DE CHAZOURNES, Laurence, MAZUYER, Emmanuelle (Dir.), Le Pacte mondial des Nations-Unies 10 ans après, Bruselas, Bruylant, 2011.

BORELLI, Silvia, "La legislation européenne contre les discriminations et le devoir de diligence des EMN”, Revue de droit compare du travail et de la sécurité sociale, 2018, $\mathrm{n}^{\mathrm{o}} 1$.

CAPRON, Michel, QUAIREL-LANOIZELÉE, Françoise, TURCOTTE, Marie-France, Iso 26000: une Norme Hors Norme?, París, Economica, 2011.

CHANTEAU, Jean-Pierre, CHENUT-MARTIN, Kathia, CAPRON, Michel (Dir.), Entreprise et responsabilité sociale en question: savoir et controverses, París, Garnier (Classiques), 2017.

CLAUWAERT, Stefan, SCHÖMANN, Isabelle, “The crisis and national labour law reforms. A mapping exercice”, European Labour Law Journal, 2012, vol. 3, nº 1.

CLARK, Gordon L., HEBB, Tessa, "Pension Fund Corporate Engagement: the fifth stage of capitalism”, Relations industrielles/Industrial Relations, invierno 2004, vol. 59, no 1.

DAUGAREILH, Isabelle (Dir.), Responsabilité sociale de l'entreprise et globalisation de l'économie, Bruselas, Bruylant, 2010.

DELMAS, Baptiste, "Peut-on contraindre les entreprises françaises à respecter les droits fondamentaux au travail à l'étranger?”, Analyse et Documents économiques, octubre 2015, n 121.

DELMAS-MARTY, Mireille, “Où va le droit ? Entre pot au noir et pilotage automatique, le droit peut-il nous guider vers une mondialité apaisée ?’, La semaine juridique, abril 2018, $n^{0} 14$. 
DE QUENAUDON, René, MARTIN-CHENUT, Kathia, La RSE saisie par le droit. Perspectives interne et internationale, París, Pedone, 2016.

DE QUENAUDON, René, Droit de la responsabilité sociétale des organisations (RSO), Bruselas, Larcier, 2014.

DILLER, Janelle, “¿Una conciencia social en el mercado mundial?: Dimensiones laborales de los códigos de conducta, el etiquetado social y iniciativas de los inversores”, Revista Internacional del Trabajo, 1999, vol. 18, nº 2.

DROUIN, Renée-Claude, "Le développement du contentieux à l'encontre des entreprises multinationales: quel rôle pour le devoir de vigilance?”, Droit social, marzo de 2016, $\mathrm{n}^{\circ}$ 3.

DORSSEMONT, Filip, VAN HOECK, Aukje, “Collective action in Labour conflicts under the Rome II Regulation”, Europe Labour Law Journal, 2011, vol. 2, nº 1 y nº 2.

GOULD, William B., FLANAGAN, J. (Dir.), International labor standards. Globalization, Trade and Public Policy, Stanford, California, Stanford University Press, 2003.

FARRARESI, Marco, Responsabilità sociale dell'impresa e diritto del lavoro, Milano, Cedam, 2012.

GENDRON, Corinne, GIRARD, Bernard (Dir.), Repenser la responsabilité sociale de l'entreprise: l'école de Montréal, París, Colin, 2013.

GIACONI, Marta, GIASANTI, Lorenzo, VARVA, Simone, "The value of social reputation the protection of MNEs' workers through consumers' eyes”, XXII Congreso mundial de derecho del trabajo y de la seguridad social (Turín, 4-7 de septiembre 2018), http://www.islssltorino2018.org/papers/

GIL Y GIL, José Luis, “Globalización y universalidad del derecho: la lex mercatoria y el derecho internacional del trabajo en el mercado global”, Revista Internacional $y$ Comparada de Relaciones Laborales y Derecho del Empleo, 2016, vol. 4, nº 2.

GIL Y GIL, José Luis, "La dimensión social de la globalización en los instrumentos de la OIT”, Revista Internacional y Comparada de Relaciones Laborales y Derecho del Empleo, 2017, vol. 5, no 1 .

HECKENDORN URSCHELER, Lukas, FOURNIER, Johanna (Dir.), Regulating Human Rights Due Diligence for Corporations, Ginebra, Schulthess, 2017. 
HODGES, Christopher, Law and Corporate Behaviour. Integrating Theories of Regulation, Enforcement, Compliance and Ethics, Oxford, Hart Publishing, 2015.

JAULT-SESEKE, Fabienne, “L’adoption du règlement nº 593/2008 (Rome I) sur la loi applicable aux obligations contractuelles: le choix de la continuité pour le contrat de travail”, Revue de Droit du Travail, oct. 2008, nº 10.

GÖKHAN KOÇER, Rüya, FRANSEN, Luc, "Codes of Conduct and the Promise of a Change of Climate in Workers Organizations”, European Journal of Industrial Relations, 2009, vol. 15, nº 3 .

KOLBEN, Kevin, “Transnational Labor Regulation and the Limits of Governance”, Theoretical Inquiries in Law, julio 2011, vol. 12, nº 2.

KUN, Attila, "How to Operationalize Open Norms in Hard and Soft Laws: Reflections Based on Two Distinct Regulatory Examples”, International Journal of Comparative Labour Law and Industrial Relations, 2018, vol. 34, $\mathrm{n}^{\circ} 1$.

LANTARÓN BARQUÍN, David, "Estándares laborales internacionales en la era de la globalización”, Trabajo y Derecho, 2017, n² 28, , pp. 35-56.

LANTARÓN BARQUÍN, David, La tutela internacional del trabajador: categorías y estrategias. El trabajo decente como telón de fondo, Valencia, Tirant lo Blanch, 2019.

MALECKI, Catherine, Responsabilité sociale des entreprises. Perspectives de la gouvernance d'entreprise durable, París, L.G.D.J., 2014.

MAZUYER, Emmanuelle (Dir), Regards croisés sur le phénomène de la responsabilité sociale de l'entreprise, París, La documentation française, 2010.

MAZUYER, Emmanuelle, "La force normative des instruments adoptés dans le cadre de la responsabilité sociales de l'entreprise”, en THIBIERGE, Catherine et al., La force normative. Naissance d'un concept, París, LGDJ, 2009.

MEYER-BISCH, Patrice, FRIBOULET, Jean-Jacques, DAVOINE, Eric (Dir.), L'effectivité des normes sociales internationales dans l'activité économique, Bruselas, Bruylant, París, LGDJ, Zúrich, Schultess, 2008.

PÄRLI, Kurt, VÖGTLI, Jasmin, "Control and Sanction of Employees on the Basis of Codes of Conduct - A Question of Basic Labour (Human) Rights?”, Labor Law Journal, 2020, vol. $71, \mathrm{n}^{\mathrm{o}} 1$ 
POSNER, Michael, NOLAN, Justine, "Can Codes of conduct play a role in promoting workers rights?”, en GOULD, William B., FLANAGAN, J. (Dir.), International labor standards. Globalization, Trade and Public Policy, Stanford, California, Stanford University Press, 2003.

ROSENBAUM RIMOLO, Jorge, "Negociación colectiva internacional. El impulso y sus frenos en Latinoamérica”, XXII Congreso mundial de derecho del trabajo y de la $\begin{array}{lllll}\text { seguridad social (Turín, 4-7 de } & \text { septiembre }\end{array}$ http://www.islssltorino2018.org/papers/

SERVAIS, Jean-Michel, "Labor Law and Cross-Border Cooperation among Unions”, en GORDON, Michael, A., TURNER, Lowell (Dir.), Transnational Cooperation among Labor Unions, Ithaca, ILR Press, Cornell University Press, 2000.

SERVAIS, Jean-Michel, "Droit international du travail et règlement des conflits transnationaux du travail”, Revue de droit comparé du travail et de la sécurité sociale, 2014, $\mathrm{n}^{\circ} 1$.

SERVAIS, Jean-Michel, “Los estándares laborales de la OIT en el contexto de la crisis”, en GIL Y GIL, José Luis, Reformas laborales frente a la crisis a la luz de los estándares de la OIT. Un análisis crítico desde las perspectivas internacional, nacional y comparada, Lisboa, Juruá Editorial, 2014.

SERVAIS, Jean-Michel, "España y las normas de la OIT o cómo renovar una bella historia”, en GIL Y GIL, José Luis (Dir.), España y la OIT. 100 años de diálogo en un mundo cambiante, Madrid, Ediciones Cinca, 2018.

VERGE, Pierre (en colaboración con DUFOUR, Sophie), Configuration diversifiée de l'entreprise et droit du travail, Saint Nicolas, Québec, P U Laval, 2003.

SANGUINETI RAYMOND, Wilfredo, VIVERO SERRANO, Juan Bautista (Dir.), La construcción del derecho del trabajo de las redes empresariales, Granada, Editorial. Comares, 2019.

SANGUINETI RAYMOND, Wilfredo, "Las cadenas mundiales de producción y la construcción de un derecho del trabajo sin fronteras”, en Asociación española de derecho del trabajo y de la seguridad social, El futuro del trabajo: cien años de la OIT, Madrid, Ministerio del trabajo, migraciones y seguridad social, 2019.

WILLIAMSON, Naomi, STAMPE-KNIPPEL, Astrid, WEBER, Tina, Corporate Social Responsibility. National Public Policies in the European Union. Compendium 2014, Luxemburgo, EU Publications Office, 2014. 


\section{Anexo}

Global Reporting Initiative: https://www.globalreporting.org

IFC, IFC Performance Standards on Environmental and Social Sustainability, Washington, 2012.

International Organization for Standardization: https://www.iso.org/home.html

Ministère de l'Europe et des affaires étrangères, La politique nationale de RSE en France. Disponible en: https://www.diplomatie.gouv.fr/fr/politique-etrangere-de-lafrance/diplomatie-economique-et-commerce-exterieur/peser-sur-le-cadre-de-regulationeuropeen-et-international-dans-le-sens-de-nos/l-engagement-de-la-france-pour-laresponsabilite-sociale-des-entreprises/la-politique-nationale-de-rse-en-france/

OIT, Documento GB.288/WP/SDG/3, Ginebra, OIT, 2003.

OIT, Codes of conduct and multinational enterprises (CD-ROM), Ginebra, 2001, disponible en: www.ilo.org/basi. 